EGU2020-20761

EGU General Assembly 2020

(c) Author(s) 2020. This work is distributed under

the Creative Commons Attribution 4.0 License.

\title{
Nature and origin of gas trapped in sediments in the Tagus River ebb-delta, off Lisbon, Portugal, the TAGUSGAS project
}

\author{
Carlos Ribeiro ${ }^{1,2}$, Pedro Terrinha ${ }^{3,4}$, Marcos Rosa $^{3}$, Marta Neres ${ }^{3,4}$, João Noiva ${ }^{3}$, Pedro Brito ${ }^{3}$, and \\ Vítor Magalhães ${ }^{3,4}$ \\ ${ }^{1}$ Dep. Geosciences, Sciences \& Technology School, University of Évora, Portugal (cribeiro@uevora.pt) \\ ${ }^{2} \mathrm{ICT}$, Earth Sciences Institute, University of Évora, Portugal \\ ${ }^{3}$ IPMA, Marine Geology, Lisboa, Portugal \\ ${ }^{4}$ IDL, Instituto Dom Luiz, FCUL, Portugal
}

The Tagus River ebb-delta is located near an important city center off Lisbon, Portugal. The Tagus delta hosts various kilometer scale landslides, the most important of which has been mapped and described with a presumable age of $\sim 11 \mathrm{ky}$ and $10 \mathrm{~km}$ in length, $4 \mathrm{~km}$ wide and $20 \mathrm{~m}$ of maximum thickness. An equivalent area of gas trapped in the sediments has also been reported (Terrinha et al., 2019).

The TAGUSGAS project aims at characterizing the nature and source of the gas. A multibeam and backscatter survey was carried out recently covering an area of $44 \mathrm{~km}^{2}$. Several morphologic artifacts were found. The magnetic survey carried out simultaneously allows at discriminating the anthropogenic origin of some of these artifacts. It also allows at distinguishing gas and igneous rock sources of acoustic blanking in the seismic reflection record.

The multibeam and backscatter basemap also serves as a tool to decide targets for seafloor sites for sample collection.

The authors would like to acknowledge the FCT financial support through project UIDB/50019/2020 - IDL and TAGUSGAS project (PTDC/CTA-GEO/31885/2017). 